\title{
ESTUDO DA ANATOMIA FOLIAR E CAULINAR E ANÁLISE DOS CONSTITUINTES QUÍMICOS DOS ÓLEOS ESSENCIAIS DAS FOLHAS E CASCAS DOS FRUTOS DE Citrus medica L.
}

Danilo Luiz dos Santos', Thatiany Castro Lobo Pereira',

Heleno Dias Ferreira', Stone de Sá', LeoniceManrique Faustino Tresvenzol',

Submetido em: 03/06/2016

Aceito em: 03/06/2016

Pedro Henrique Ferri', José Realino de Paula ${ }^{1 *}$, Tatiana de Sousa Fiuza',

Publicado em: 31/12/2016

Leonardo Luiz Borges ${ }^{2}$

'Universidade Federal de Goiás

2Pontifícia Universidade Católica de Goiás

‘E-mail: pjrpaula@gmail.com

\section{Resumo}

Citrus medica L. (Rutaceae) é utilizada popularmente como anti-inflamatória, anti-histamínica, diurética e calmante. Os objetivos deste trabalho foram: realizar o estudo anatômico das folhas e caules, determinar o teor de umidade do pó das folhas e das cascas dos frutos e analisar os componentes dos óleos essenciais das folhas e cascas dos frutos de C. medica. O estudo anatômico das folhas e dos caules foi realizado de acordo com as técnicas botânicas convencionais. O teor de umidade foi feito utilizando um analisador de umidade. Os óleos essenciais das folhas e das cascas foram obtidos por hidrodestilação em um aparelho de Clevenger e analisados por CG/EM. Entre os aspectos anatômicos foliares destacam-se as cavidades secretoras contendo material lipídico, estômatos paracíticos e cristais prismáticos. Os componentes majoritários dos óleos essenciais das folhas foram E-cariofileno (16,82\%), limoneno (12,35\%) e acetato de geranila $(11,75 \%)$; e das cascas dos frutos, o limoneno $(85,35 \%$ a $90,14 \%)$.

Palavras-chave: Rutaceae, limoneno, cidra.

\section{Study of leaf and stem anatomy and analysis of chemical constituents of essential oils of leaves and fruit} peels of Citrus medica $L$.

\begin{abstract}
Citrus medica L. (Rutaceae) is used in folk medicine as anti-inflammatory, antihistamine, diuretic and sedative. The aims of this study were: performing anatomical studies of leaves and stems; determine the moisture content of the powder of leaves and fruit peels; analyze the components of the essential oils from the leaves and fruit peels of $C$. medica. The anatomical study of the leaves and stems was performed in accordance with conventional botanical techniques. The determination of moisture content was done using a moisture analyzer. The essential oils of leaves and fruit peels were obtained by hydro distillation in a Clevenger apparatus and analyzed by GC/MS. The important anatomical aspects of $C$. medica were secretory cavities with lipid material, paracytic stomata and prismatic crystals. The major components identified in the essential oil of the leaves were E-caryophyllene $(16.82 \%)$, limonene $(12.35 \%)$ and geranyl acetate $(11.75 \%)$, and of the fruit peels was limonene $(85.35 \%$ to $90.14 \%)$.
\end{abstract}

Keywords: Rutaceae, limonene, cider. 


\section{Estudio de la anatomía foliar y caulinar y análisis de los constituyentes químicos de los aceites esenciales de las hojas y cáscaras de los frutos Citrus medica $L$.}

\section{Resumen}

Citrus medica L. (Rutaceae) se utiliza popularmente como antiinflamatorio, antihistamínico, diurético y calmante. Los objetivos de este estudio fueron realizar el estudio anatómico de las hojas y tallos, determinar el contenido de humedad del polvo de las hojas y cáscaras de los frutos y analizar los componentes de los aceites esenciales de las hojas y la corteza de los frutos de C. medica. El estudio anatómico de las hojas y los tallos fue realizado de acuerdo con las técnicas botánicas convencionales. El contenido de humedad se hizo usando un analizador de humedad. Los aceites esenciales de hojas y la corteza fueron obtenidos por hidrodestilación en un aparato de Clevenger y se analizaron por GC/EM. Entre los aspectos anatómicos foliares de destacan las cavidades secretoras que contienen material lipídico, estomas paracíticos y cristales prismáticos. Los componentes principales de los aceites esenciales de las hojas eran E-cariofileno $(16,82 \%)$, limoneno $(12,35 \%)$ y geranila $(11,75 \%)$ y cáscaras de los frutos el limoneno $(85,35 \%$ a $90,14 \%)$.

Palabras-clave: Rutaceae, limoneno, cidra.

\section{INTRODUÇÃO}

Citrus medica L. (sinonímia Aurantium medicum (L.) M. Gómez) pertence à família Rutaceae, subfamília Rutoideae e tribo Aurantieae ${ }^{(1)}$. Popularmente é conhecida como cidra ${ }^{(2)}$, baranimbu, matulunga, gajanimbe ${ }^{(3)}$.

É uma arvoreta com cerca de 3 a 6 m de altura; ramos curtos, grossos, com espinhos de 3 a $4 \mathrm{~cm}$ comprimento nas axilas foliares ${ }^{(3)}$. As folhas são simples, alternas, com forma variando de ovalada-lanceolada, oblonga e elíptica, atingindo até $15 \mathrm{~cm}$ de comprimento, margem serreada, ápice arredondado; são glabras e lustrosas com coloração verde intensa e pontuações translúcidas ${ }^{(4)}$. Os pecíolos são curtos e não alados. As flores são brancas, perfumadas, pentâmeras; corola dialipétala, 1,5 a $2 \mathrm{~cm}$ comprimento; 10 estames brancos; ovário súpero, estilete terminal. O fruto é do tipo baga medindo até $30 \mathrm{~cm}$ de comprimento; apresenta uma coloração verde-amarelada, formato elipsoide, geralmente com pequeno mamilo apical; a casca é grossa, rugosa e com glândulas oleosas aderidas ao epicarpo; sua polpa é suculenta, doce ou ácida. As sementes são pequenas e lisas(4).

Em Bangladesh, Índia e Indonésia, a casca da cidra é ingerida crua com arroz ${ }^{(5)}$. Na Espanha, as cascas da cidra são utilizadas como flavorizantes de medicamentos e na Guatemala, como flavorizantes de refrigerantes ${ }^{(6)}$. No Brasil, a casca da cidra é utilizada tradicionalmente na preparação de doces caseiros ${ }^{(2)}$.

Várias partes da planta são empregadas na medicina tradicional indiana: os frutos maduros são utilizados para dor de garganta e ouvido, tosse, asma, escorbuto, hemorroidas, como tônico cardíaco e contra vômitos; o extrato aquoso do fruto é sedativo e o chá das folhas é utilizado para induzir o sono(7); as sementes são empregadas como vermífugas, como estimulantes e como tônico cardíaco ${ }^{(3,8)}$.

Estudos realizados com indivíduos de C. medica detectaram nos frutos ações antimutagênica, anticancerígena ${ }^{(9)}$, analgésica ${ }^{(10)}$, anti-inflamatória, antioxidante, inibidora da alfa-glicosidase ${ }^{(11)}$, antiúlcera ${ }^{(12)}$ e cardioprotetora ${ }^{(13)}$; nas cascas dos frutos, atividades antioxidante, analgésica e anti-inflamatória(14); nas sementes, atividades antidiabética, hipocolesterolêmica e hipolipidêmica ${ }^{(15)}$; e nas folhas, atividades anti-helmíntica ${ }^{(16)}$ e estrogênica ${ }^{(17)}$. 
Essien e Essien ${ }^{(18)}$ verificaram que o óleo essencial das folhas da C. medica exibiu atividade fungiotóxica contra 14 espécies de fungos, enquanto o extrato etéreo das folhas apresentou atividade anti-helmíntica contra Pheretima posthumad ${ }^{(16)}$. Patil e Patil (19) verificaram ausência de toxicidade do extrato etanólico e benzênico das sementes dessa espécie em camundongos.

Como visto na literatura, a C. medica é utilizada popularmente no tratamento de algumas enfermidades, mas é necessário estabelecer parâmetros para a identificação da planta, bem como da droga vegetal, contribuindo com dados padrão para o controle de qualidade. Os parâmetros de identidade botânica são feitos através de ensaios macro e microscópicos, da parte utilizada como medicinal, bem como pela presença dos constituintes químicos característicos da espécie ${ }^{(20)}$. A análise botânica é rápida e auxilia a verificar a autenticidade da amostra, a possível contaminação por outras espécies vegetais ou outras partes da planta, com o mínimo de equipamentos e reagentes, tornando-se econômica e não poluente, desde que se tenha matériaprima íntegra(21). A análise de amostras pulverizadas é mais complexa e exige o reconhecimento de estruturas microscópicas características e diferenciais, bem como da complementação com as análises químicas(20). Entretanto, a microscopia do pó auxilia a prever e a justificar a presença de certos elementos celulares e mesmo detectar eventuais contaminações pela presença de tecidos que, em princípio, não deveriam figurar no pó de uma determinada droga vegetal(21).

Diante do exposto e da importância da espécie como medicinal, os objetivos do trabalho foram: realizar o estudo anatômico das folhas e caules de C. medica; determinar o teor de umidade do pó das folhas e das cascas dos frutos; identificar os componentes químicos dos óleos essenciais das folhas; e determinar a composição e a variabilidade dos componentes químicos dos óleos essenciais das cascas dos frutos de C. medica.

\section{METODOLOGIAS}

As folhas e caules de Citrus medica L. (Rutaceae) foram coletadas no município de Pirenópolis (15 00' 14,5" Sul, $49^{\circ}$ 54'16,4" Oeste e 829m de altitude), no Estado de Goiás, Brasil (agosto 2009). Os frutos foram coletados nos municípios de

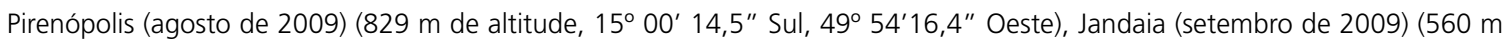

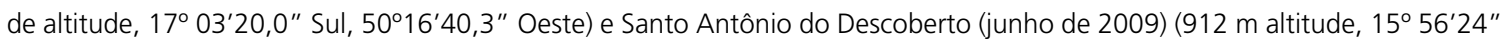
Sul, 48॰15'18" Oeste)

A planta foi identificada pelo Prof. Dr. José Realino de Paula, da Faculdade de Farmácia da Universidade Federal de Goiás; e uma exsicata foi depositada no Herbário da Unidade de Conservação da UFG sob registros UFG/41493 (Pirenópolis), UFG/41496 (Jandaia), UFG/41405 (Santo Antônio do Descoberto).

Os frutos foram descascados e as cascas, bem como as folhas frescas, foram utilizadas para extração dos óleos essenciais.

Para a triagem fitoquímica e a microscopia de pó, as folhas e as cascas dos frutos foram secas em estufa com circulação de ar a uma temperatura de $40^{\circ} \mathrm{C}$ e trituradas em moinho de faca.

\section{Estudo anatômico}

Para o estudo anatômico foram utilizadas folhas provenientes do segundo e terceiro nós e ramos caulinares ( $2^{\circ}$ entrenó) recém-coletados. As secções transversais e paradérmicas foram realizadas à mão livre, com auxílio de lâmina de aço inoxidável. Foram realizadas secções paradérmicas das faces adaxial e abaxial da lâmina foliar e secções transversais da lâmina foliar (região dos bordos e terço médio da região da internervura e da nervura principal); do pecíolo (região mediana) e dos ramos caulinares. Após a diafanização com solução de hipoclorito de sódio a $2 \%$, as secções foram lavadas em água destilada, solução de ácido acético a 5\% e submetidas à coloração com azul de Alcian/safranina 9:1 $1^{(22)}$ e testes histoquímicos com: cloreto férrico(23) (coloração negro-azulada indica presença de compostos fenólicos), Steinmetz - reagente polivalente ${ }^{(24)}$ (coloração azulpreto presença de amido; coloração vermelho alaranjado presença de lipídeos; coloração vermelha evidencia cutina; coloração 
dourada evidencia lignina; os cristais de oxalato de cálcio permanecem incolores) e lugol(23) (coloração azul-negra ou marrom muito escuro indica presença de amido).

Para a análise microscópica do pó obtido das folhas e cascas dos frutos, uma pequena quantidade de cada amostra foi colocada em uma lâmina à qual se adicionou uma gota do reagente de Steinmetz. O material foi coberto com lamínula e observado em microscópio de luz.

O registro fotográfico das estruturas anatômicas foi realizado em fotomicroscópio (Zeiss-Axiostar plus) com máquina fotográfica digital acoplada (Canon Power Shot G10), utilizando o software Axion Vision 4.8.

\section{Triagem Fitoquímica}

Para a triagem fitoquímica foram pesquisados: heterosídeos antraquinônicos (formação de fenatos de amônio), cumarinas (hidrólise alcalina e observação em luz ultravioleta), esteroides e triterpenos (reações de Liebermann-Burchard e Salkowski); heterosídeos digitálicos (reações de Liebermann-Burchard, Kedde e Keller-Kiliani); amido (lugol); alcaloides (reativos de Mayer, Dragendorff, Bouchardat, Bertrand, Hager, ácido tânico a 1\%); heterosídeos flavonoides (reação de Shinoda; oxalo-bórica; com $\mathrm{H}_{2} \mathrm{SO}_{4}$ conc.; com hidróxidos alcalinos; cloreto de alumínio e cloreto férrico); heterosídeos saponínicos (índice de espuma); taninos (reações com gelatina, sulfato de quinina $1 \%$, acetato de cobre $4 \%$, cloreto férrico $2 \%$ e hidróxido de sódio a $20 \%$ ) e metilxantinas (reação de murexida) ${ }^{(21,24)}$.

A determinação do teor de umidade foi realizada em um analisador de umidade que produz radiação na região do infravermelho por meio de uma lâmpada de halogênio (Ohaus modelo MB35)(25). Inicialmente retirou-se a umidade do equipamento e pesou-se $0,5 \mathrm{~g}$ dos pós das folhas e das cascas dos frutos. O material foi distribuído uniformemente no coletor e a cuba foi aquecida até peso constante. Anotou-se o valor da umidade, em percentual, diretamente do display do aparelho. Os ensaios foram realizados em triplicata e calculou-se a média e o coeficiente de variação (CV).

\section{Obtenção e análise do óleo essencial}

Os óleos essenciais das folhas (150g) e cascas dos frutos (150g) da C. medica foram obtidos por hidrodestilação em um aparelho de Clevenger por duas horas. Os óleos essenciais foram dessecados com sulfato de sódio anidro e armazenados em freezer a $-10^{\circ} \mathrm{C}$. Os óleos essenciais foram submetidos a análise por cromatografia gasosa acoplada a espectrometria de massas (CG/EM) no aparelho Shimadzu QP5050A utilizando uma coluna capilar de sílica fundida (CBP-5; 30m x 0,25mm x 0,25 $\mu \mathrm{m}$ ), mantendo-se um fluxo de $1 \mathrm{~mL} / \mathrm{min}$ de Hélio, como gás de arraste, aquecimento com temperatura programada $\left(60^{\circ} \mathrm{C}\right.$ por $2 \mathrm{~min}$, $3^{\circ} \mathrm{C}$ por min até $240^{\circ} \mathrm{C}, 10^{\circ} \mathrm{C}$ por min até $280^{\circ} \mathrm{C}$ e $280^{\circ} \mathrm{C}$ por $10 \mathrm{~min}$ ), e energia de ionização de $70 \mathrm{eV}$. Volume de injeção de $1 \mu \mathrm{L}$ das amostras diluídas em diclorometano (20\% p/v) no modo Split com uma razão de 1:50.

A identificação dos componentes dos óleos foi baseada no índice de retenção linear (Índice de Kovats), calculado em relação ao tempo de retenção de uma série homologa de n-alcanos $\left(C_{8}-C_{32}\right)^{(26)}$ e no padrão de fragmentação observado nos espectros, por comparação com amostras autênticas ${ }^{(27)}$ ou por comparação com uma base de dados - MS computadorizada utilizando a biblioteca ${ }^{(28)}$.

Para calcular o rendimento dos óleos essenciais foi feita uma relação entre o volume do óleo essencial obtido no aparelho de Clevenger e a quantidade de folhas e de epicarpos utilizados ( $\mathrm{v} / \mathrm{p}$ ) em porcentagem.

\section{Análise estatística}

Para verificar a variabilidade química entre os compostos químicos dos óleos essenciais das cascas dos frutos foi utilizada a análise de variância (ANOVA), segundo um critério: valores de $p \leq 0,05$ foram considerados estatisticamente significantes. 


\section{RESULTADOS}

\section{Estudo anatômico}

A folha de C. medica é glabra e possui epiderme unisseriada, com células de paredes retas a levemente encurvadas em ambas as faces (Figura 1A), revestida com cutícula delgada (Figura 1C). É hipoestomática, com estômatos do tipo paracíticos (Figura 1B).

O mesofilo é dorsiventral, com parênquima paliçádico formado por cerca de três a quatro camadas de células (Figuras 1CE), apresentando compostos fenólicos (Figura 1E); o parênquima lacunoso ocupa 2/3 do mesofilo, com nove a onze camadas de células (Figuras 1C, 1D). Apresenta feixe vascular colateral com calota esclerenquimática externa ao floema (Figura 1D). Cavidades secretoras com material lipídico (Figura 1C) e cristais prismáticos (Figura 1F) ocorrem ao longo do mesofilo.

Figura 1. Lâmina foliar de C. medica. A - Face adaxial da epiderme em secção paradérmica. B - Face abaxial da epiderme evidenciando estômatos do tipo paracítico em secção paradérmica. C - Aspecto geral do mesofilo. Presença de cavidade secretora com material lipídico evidenciado pela reação histoquímica de Steinmetz. D - Aspecto geral do mesofilo com destaque para o feixe vascular. E - Aspecto geral do mesofilo evidenciando compostos fenólicos no parênquima paliçádico pela reação com cloreto férrico. F - Cristais prismáticos na epiderme, nos parênquimas paliçádicos lacunosos evidenciados sob luz polarizada. Ce - células da epiderme, Cf - compostos fenólicos, $\mathrm{Cp}$ - cristal prismático, Cs - cavidade secretora, Cu - cutícula, Ep - epiderme, Es - estômato, Ces - calota esclerenquimática, Ml - material lipídico, Pl - parênquima lacunoso, Pp - parênquima paliçádico, Xi - Xilema, A-D - Azul de Alcian/Safranina, C - Steinmetz, E - Cloreto férrico.
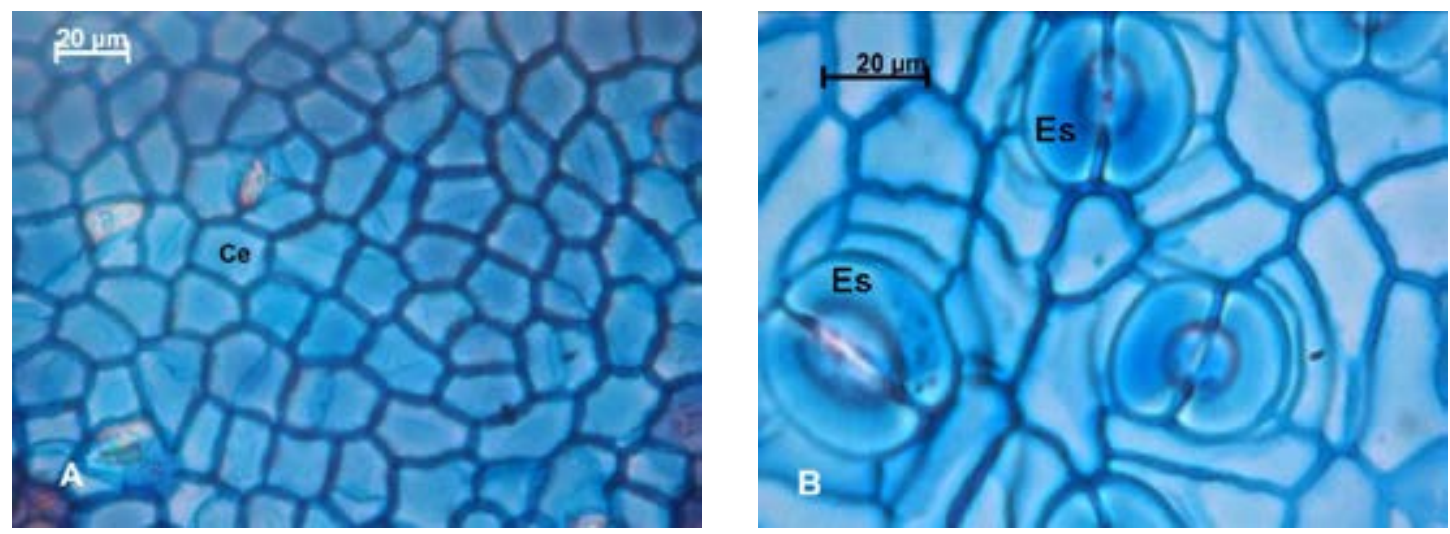

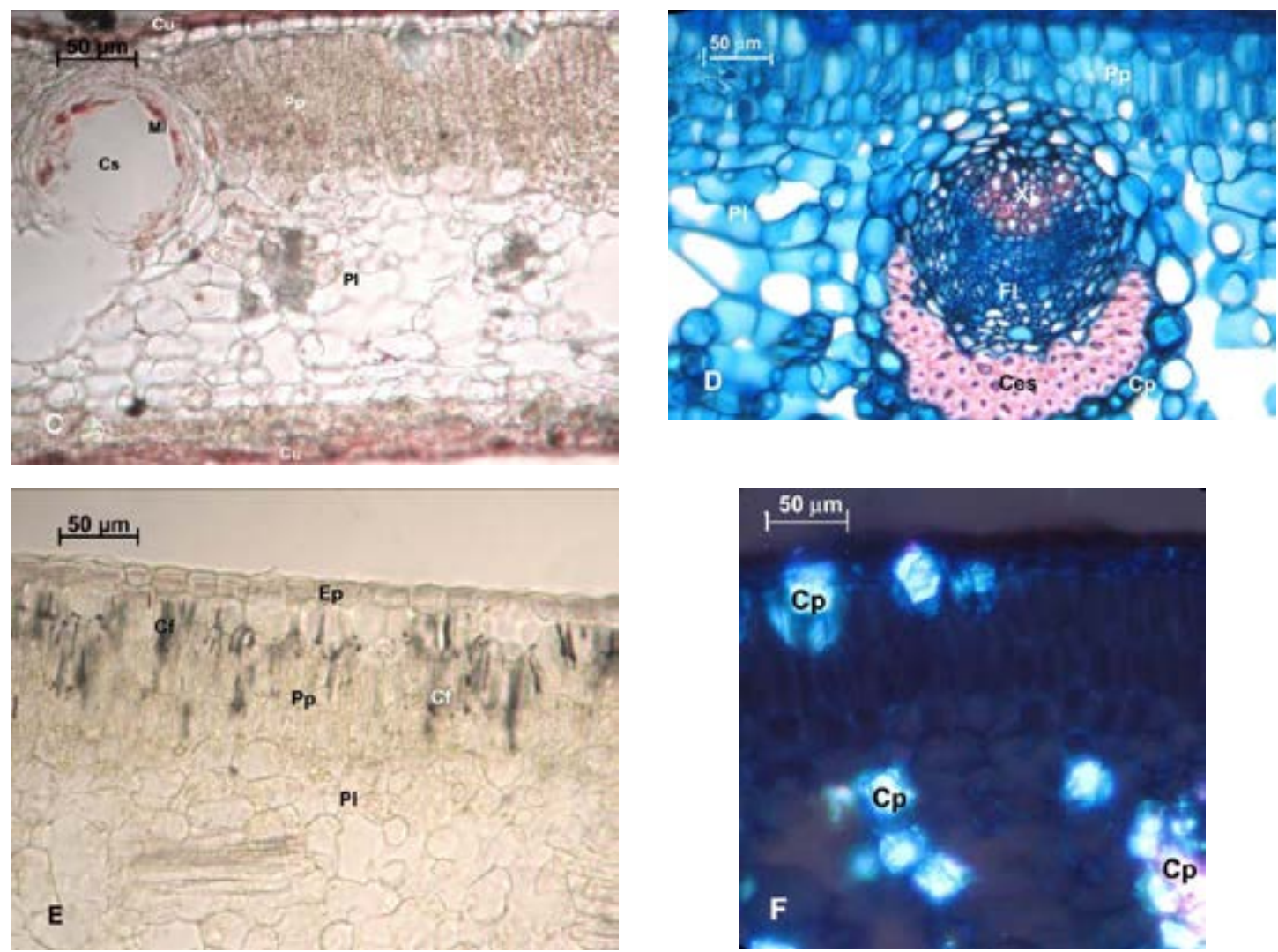

A nervura principal, em secção transversal, possui contorno convexo em ambas as faces (Figura 2A). Sob a epiderme ocorre colênquima angular (Figura 2A e 2B), seguido do parênquima cortical. Observam-se dois feixes vasculares colaterais côncavos, um central maior e outro de menor calibre (Figura 2D, seta), formando um arco aberto, com faixa esclerenquimática externa ao floema, interrompida por células parenquimáticas (Figura 2D). Ocorrência de cristais prismáticos em toda a nervura principal (Figura 2E). O parênquima medular tem células de tamanhos variados com campos primários de pontuações (Figura 2F). 
Figura 2. Secções transversais da nervura principal de C. medica. A - Aspecto geral. B - Detalhe da região cortical. C Detalhe da região cortical evidenciando compostos fenólicos no colênquima pela histoquímica de Steinmetz. D - Feixes vasculares maior e menor (seta). E - Nervura principal evidenciando cristais prismáticos sob a luz polarizada. F - Região medular. Cf - Compostos fenólicos, Co - colênquima, Cp - cristal prismático, Cpp - campos primários de pontoações, Cu cutícula, Cv - câmbio vascular, Ep - epiderme, Es - esclerênquima, Fl - floema, Pc - parênquima cortical, Pm - parênquima medular, Xi - xilema, A, B, D, E e F - Azul de Alcian/Safranina, C - Steinmetz.
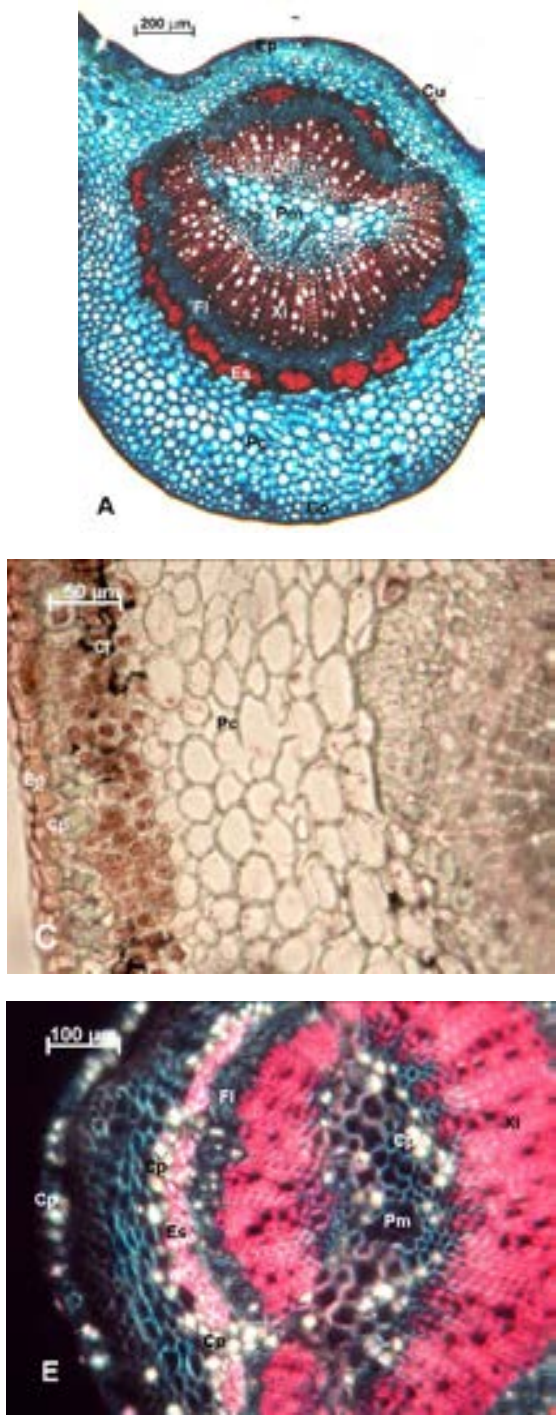
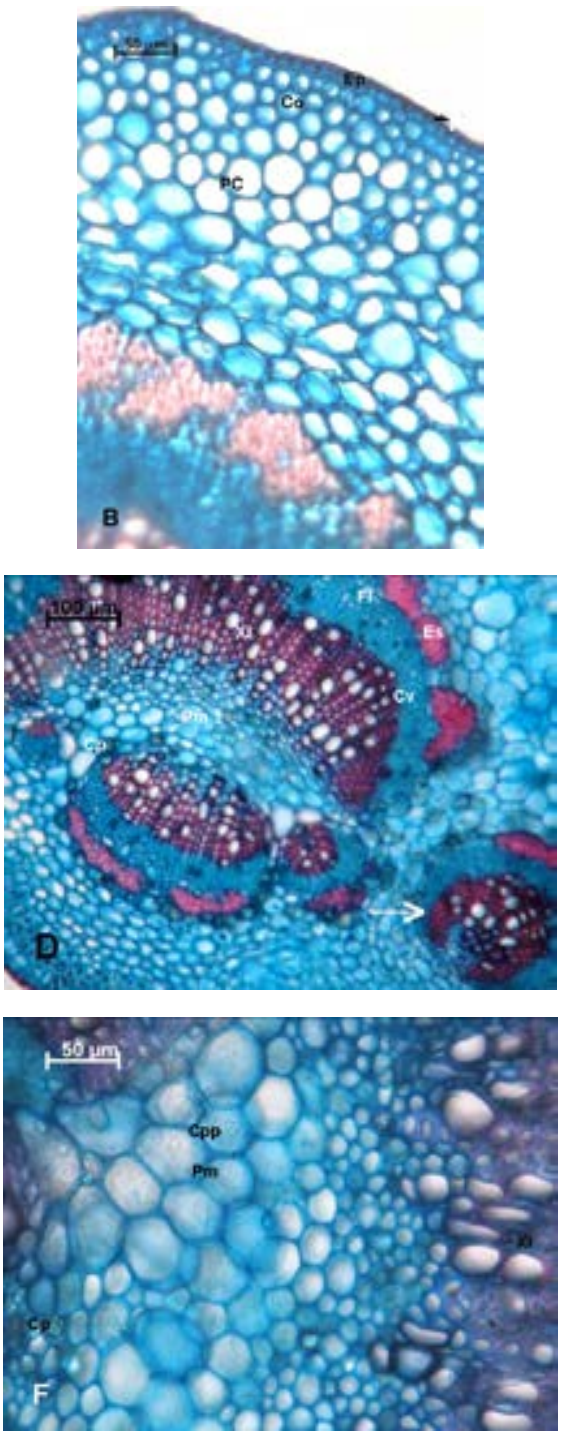
O bordo, região basal da lâmina foliar, apresenta parênquima paliçádico e lacunoso entre o último feixe vascular e a epiderme. Presença de cristais prismáticos (Figura 3A).

O bordo, região mediana da lâmina foliar, possui cristais prismáticos, parênquima paliçádico contendo compostos fenólicos entre o último feixe vascular e a epiderme (Figura 3B) e cavidade secretora com material lipídico (Figura 3C).

O bordo, região apical da lâmina foliar, apresenta parênquima clorofiliano entre o último feixe vascular e a epiderme (Figura 3D).

Figura 3. Secções transversais da lâmina foliar de C. medica nas regiões dos bordos. A - Bordo da região basal da lâmina foliar com histoquímica de Steimetz evidenciando cutícula delgada (cutina) e cristais de oxalato de cálcio (incolor). B Bordo da região mediana da lâmina foliar com histoquímica com cloreto férrico evidenciando compostos fenólicos no parênquima paliçádico. C - Bordo da região mediana da lâmina foliar com histoquímica de Steimetz evidenciando material lipídico no interior da cavidade secretora e cutícula (cutina). D - Bordo apical. Cf - compostos fenólicos, Co - Colênquima, Cp - cristal prismático, Cs - cavidade secretora, Cu - cutícula, Ep - epiderme, Ml - material lipídico, PC - parênquima clorofiliano, PI - parênquima lacunoso, Pp - parênquima paliçádico, Fv - feixe vascular. A e C - Steinmetz. B - Cloreto férrico. D - Azul de Alcian/safranina.
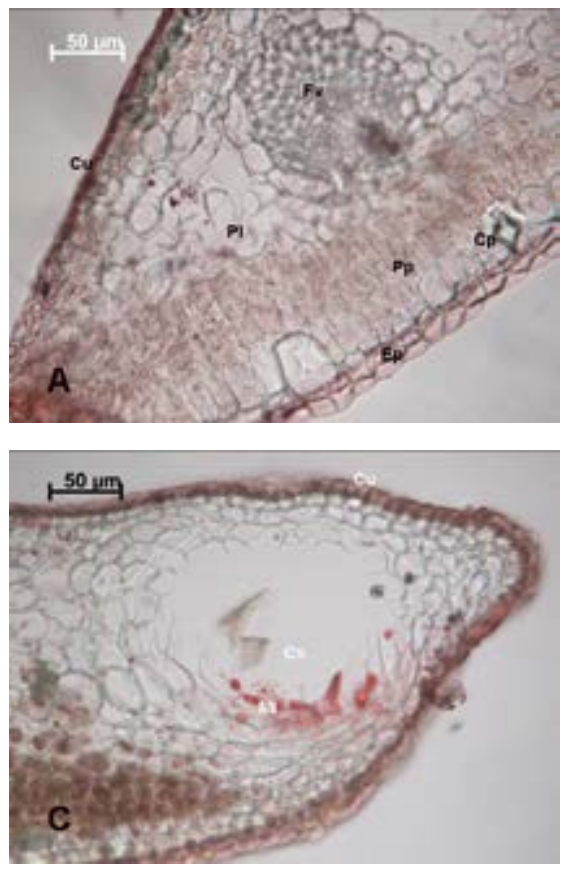
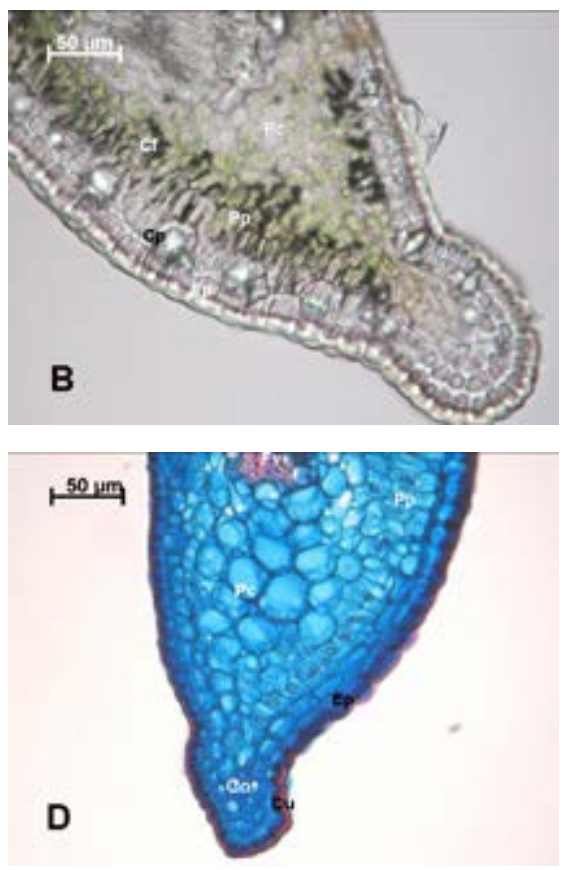

O pecíolo possui forma plano-convexa. A epiderme é unisseriada, seguida de parênquima cortical com numerosos cristais prismáticos (Figura 4A). O sistema vascular, em início de crescimento secundário, apresenta-se em forma de arco com extremidades invaginadas (Figura 4B). Observam-se floema secundário e raios parenquimáticos uni a bisseriados no xilema 
(Figura 4C). Verificam-se no parênquima medular células de tamanhos variados com campos primários de pontuações e cristais prismáticos no floema e no parênquima medular (Figura 4D).

Figura 4. Secções transversais do pecíolo de C. medica. A - Região cortical evidenciando numerosos cristais prismáticos - luz polarizada. B - Sistema vascular aspecto geral. C - Sistema vascular evidenciando raios parenquimáticos (seta). D Região medular com histoquímica de Steimetz evidenciando células de tamanhos variados com campos de pontoações primários e cristais prismáticos. Cp - cristal prismático, Cv - câmbio vascular, Fl - floema, Pc - parênquima cortical, Pm - parênquima medular, Cpp - campos primários de pontoações primárias, Xis - xilema secundário. A-C - Azul de alcian/ safranina. D-Steinmetz.
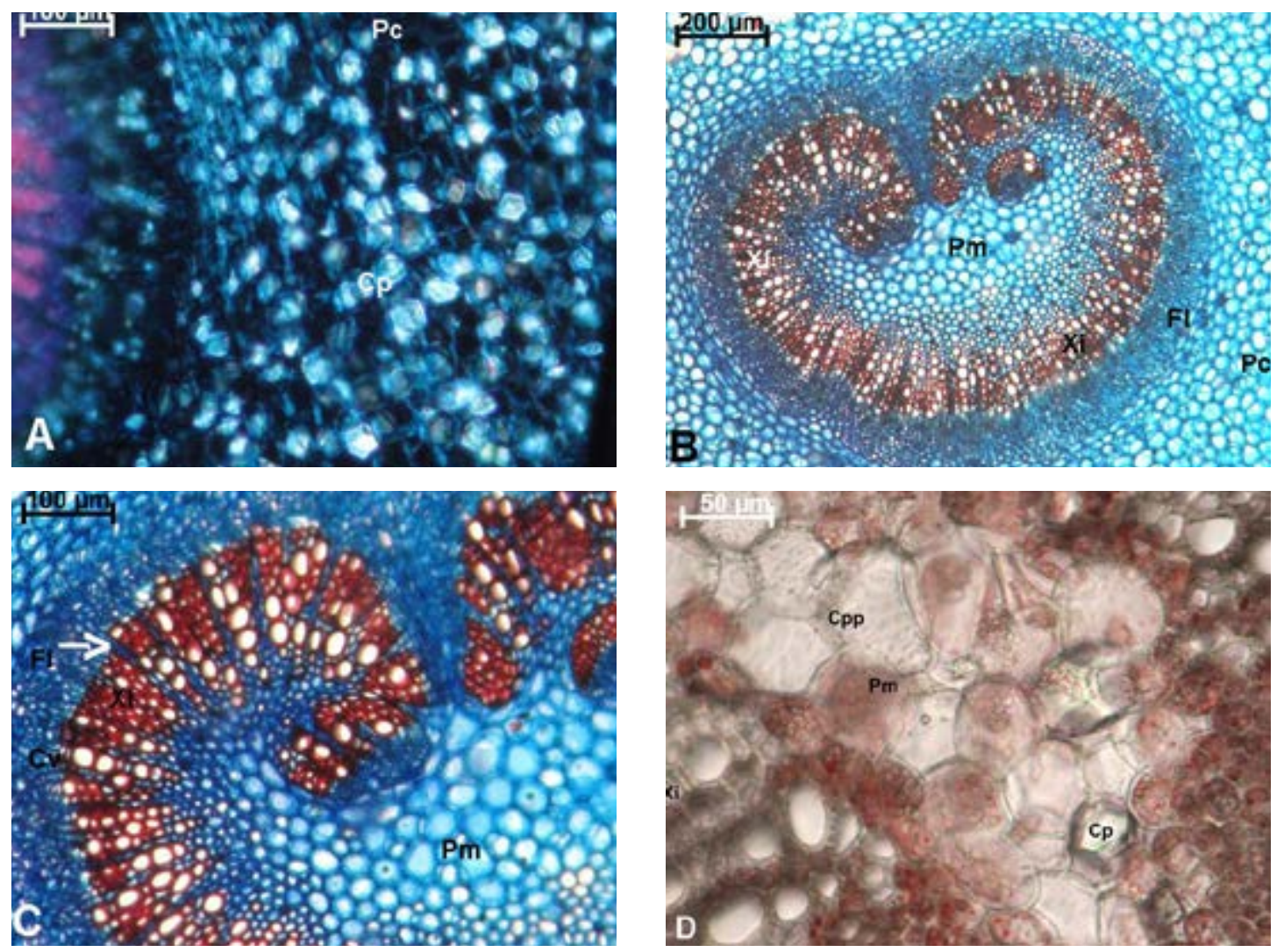

O caule na região do segundo entrenó, em secção transversal, tem forma oval-elíptica. A epiderme é unisseriada, revestida por cutícula delgada e hipoderme (Figura 5A). Na região cortical ocorrem cavidades secretoras com material lipídico próximo à epiderme (Figuras 5A e 5B), colênquima angular com três a cinco camadas de células, seguido de parênquima com células de tamanhos variados (Figuras 5A e 5B). Externamente ao floema, faixas esclerenquimáticas são interrompidas por células 
parenquimáticas. O sistema vascular encontra-se em início de crescimento secundário (Figuras 5A e 5C). O parênquima medular contém células de tamanhos variados com campos primários de pontoações (Figura 5D).

Figura 5. Secções transversais do caule de C. medica na região do 20 entrenó. A - Aspecto geral. B - Região cortical com reação de Steimetz evidenciando material lipídico no interior da cavidade secretora e cutícula delgada (cutina). C - Sistema vascular evidenciando floema secundário, câmbio vascular e xilema. D - Detalhe do parênquima medular evidenciando campos primários de pontoações. Co - colênquima, Cs - cavidade secretora, Cu - cutícula, Cv - câmbio vascular, Ep epiderme, FI - floema, Fv - Feixe vascular, Hip - hipoderme (seta), Ml - material lipídico, Pc - parênquima cortical, Pm - parênquima medular, Cpp - campos primários de pontoações (seta), Xi - xilema. A e C - Azul de Alcian/safranina. B e D - Steinmetz.
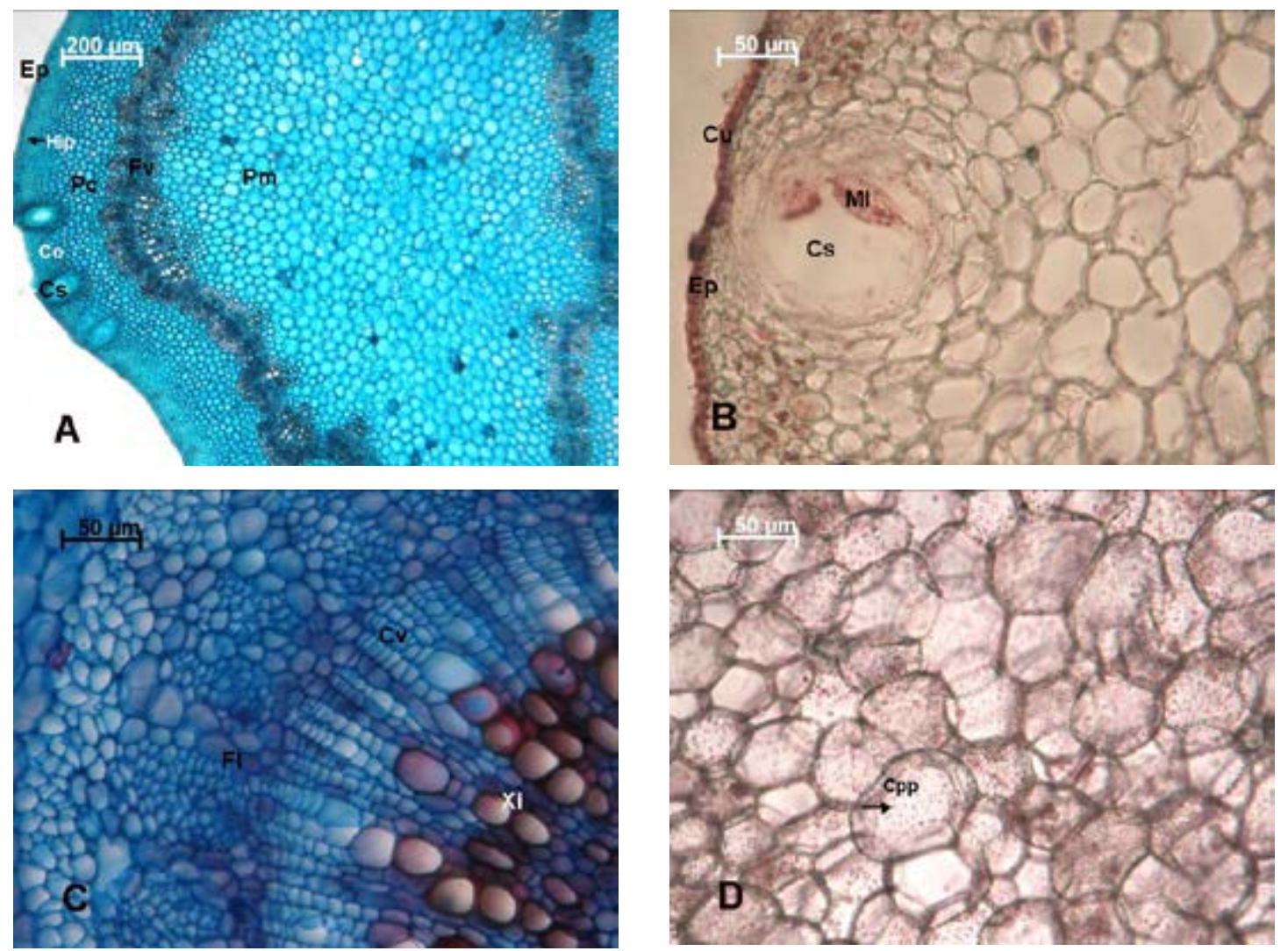

Na análise microscópica do pó obtido das folhas foram observados feixes vasculares com espessamento em anel (Figura $6 \mathrm{~A})$, cristais prismáticos (Figura 6B), estômatos paracíticos e células da epiderme contendo material lipídico (Figura 6C).

Na microscopia do pó das cascas dos frutos foram visualizadas células da epiderme com paredes retas levemente encurvadas (Figura 6D), grãos de amido (Figura 6E) e cristais prismáticos (Figura 6F). 
Figura 6. Microscopia de pó das folhas e das cascas dos frutos. A, B e C (folhas). D, E e F (cascas dos frutos). A - Feixes vasculares com espessamento em anel. B - Cristais prismáticos evidenciados em luz polarizada. C - Fragmento da face abaxial da lâmina foliar evidenciando estômatos. D - Fragmento da casca evidenciando células epidérmicas. E - Grãos de amido evidenciados pela histoquímica com reagente de Steinmetz. F - Cristais prismáticos evidenciados em luz polarizada. Ce - célula epidérmica, Cp - cristais prismáticos, Es - estômato, Fv - feixes vasculares com espessamento em anel, Ga grãos de amido. Steinmetz.
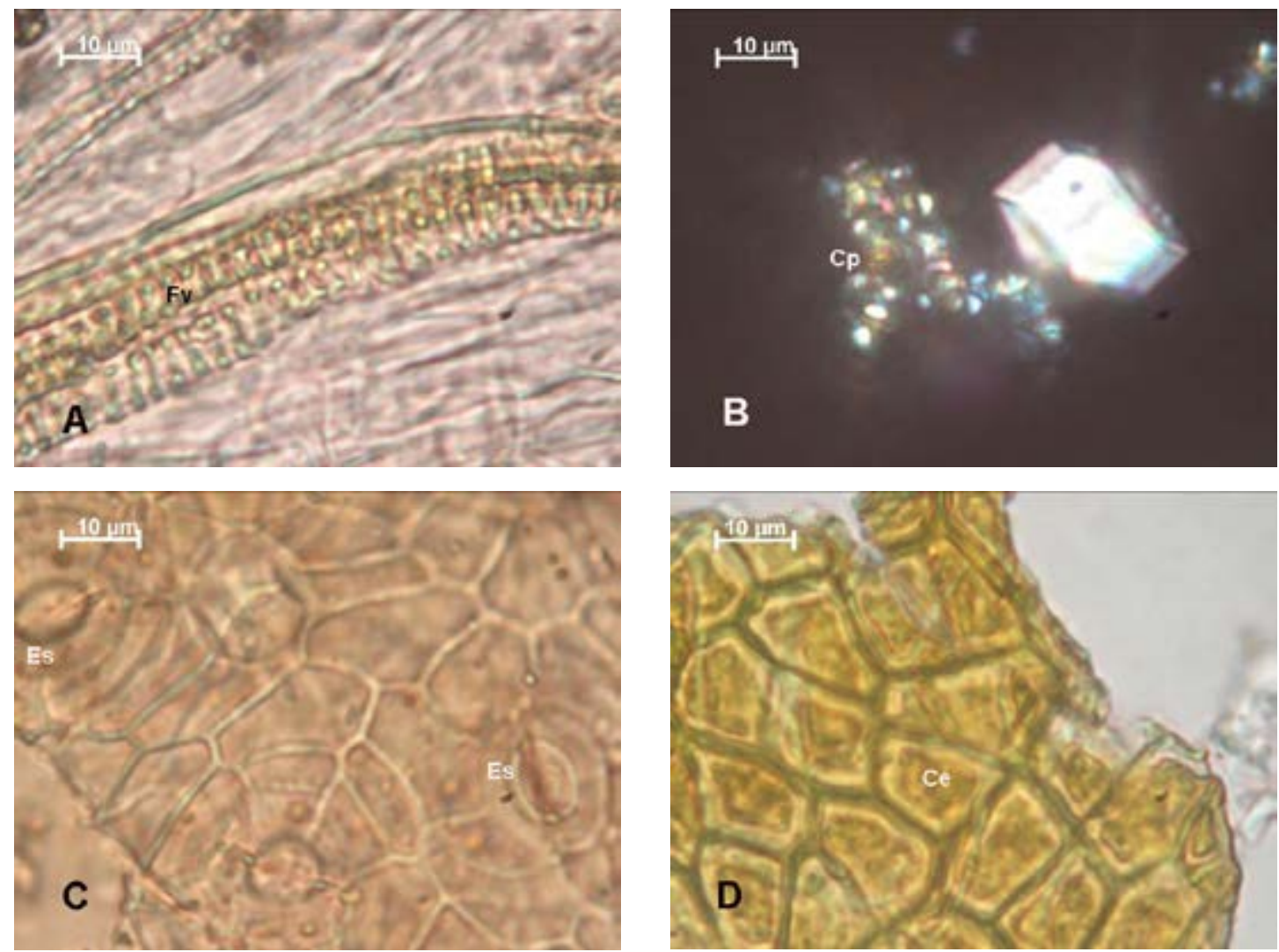

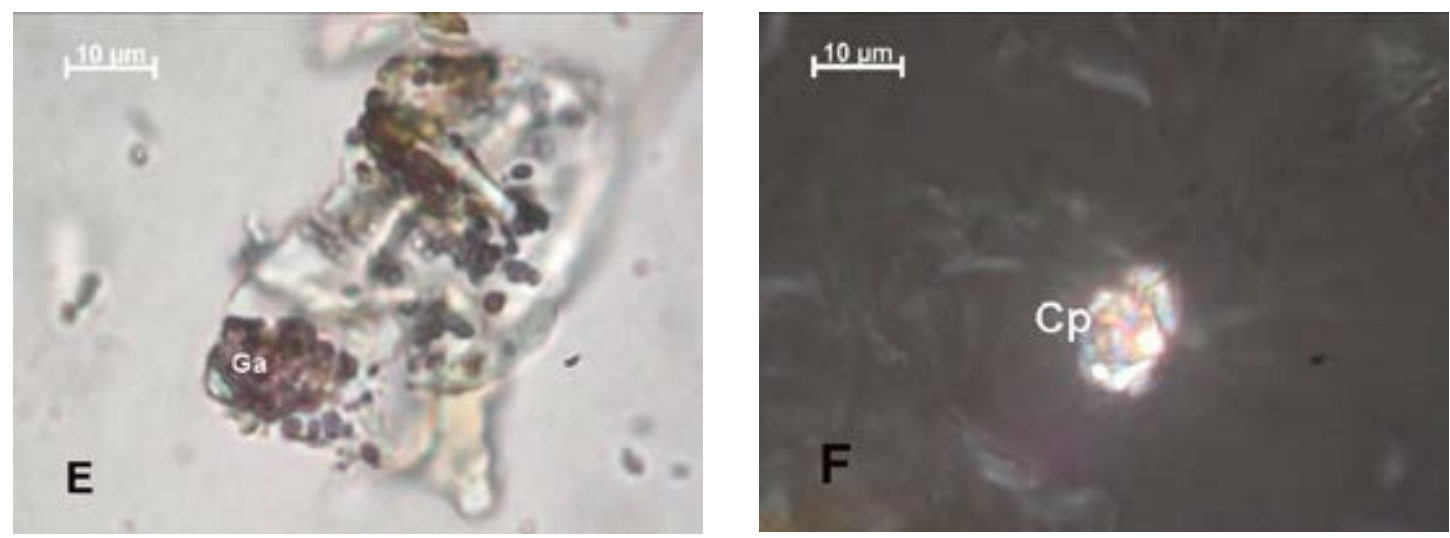

\section{Triagem fitoquímica}

No pó das folhas da C. medica foram detectados flavonoides, triterpenos, cumarinas e saponinas; e no pó das cascas dos frutos, flavonoides, triterpenos, cumarinas e amido.

O teor de umidade médio para o pó das folhas foi de 8,17\%, com coeficiente de variação (CV) de 2,22 e para o pó das cascas dos frutos de $6,22 \%, \mathrm{CV}$ de 3,90 .

\section{Óleos essenciais}

O rendimento do óleo essencial foi de 1,6\% para as folhas e de 3,5\% em média para a casca dos frutos.

No óleo essencial das folhas de C. medica foram identificados 27 compostos, sendo os componentes majoritários o E-cariofileno (16,82\%), o limoneno (12,35\%) e o acetato de geranila $(11,75 \%)$ (Tabela 1). No óleo essencial das cascas dos frutos foram identificados, no total, 23 compostos químicos (21 na amostra de Pirenópolis, 12 na de Jandaia e 17 na de Santo Antônio do Descoberto), em sua maioria hidrocarbonetos monoterpênicos $(>90 \%)$. Desses compostos, dez ( $\beta$-pineno, limoneno, $\beta$-mirceno, Z- $\beta$-ocimeno, E- $\beta$-ocimeno, citronelol, nerol, geraniol, trans-cadina-1(6),4-dieno, $\beta$-bisaboleno) estavam presentes em todas as amostras, sendo o limoneno o componente majoritário (85,35\% a 90,14\%) (Tabela 2). Não houve variabilidade significativa entre os componentes químicos majoritários das amostras de óleo essencial das cascas de $C$. medica coletadas em Pirenópolis, Jandaia e Santo Antônio do Descoberto/GO (Tabelas 3 e 4).

Tabela 1. Compostos identificados no óleo essencial das folhas de C. medica e seus respectivos teores expressos em porcentagens relativas (\%)

\begin{tabular}{|ccc|}
\hline Constituintes & KI & Óleo essencial das folhas de C. medica (\%) \\
\hline Sabineno & 975 & 0,30 \\
\hline$\beta$-Pineno & 979 & 2,15 \\
\hline Mirceno & 990 & 0,40 \\
\hline
\end{tabular}

continua... 


\begin{tabular}{|c|c|c|}
\hline Constituintes & KI & Óleo essencial das folhas de C. medica (\%) \\
\hline Limoneno & 1029 & 12,35 \\
\hline 1,8-Cineol & 1031 & 0,59 \\
\hline Linalol & 1096 & 1,44 \\
\hline n-Nonanal & 1100 & 0,42 \\
\hline Citronelal & 1153 & 5,16 \\
\hline$\alpha$-Terpineol & 1188 & 0,57 \\
\hline Citronelol & 1225 & 2,26 \\
\hline Acetato de linalila & 1257 & 3,99 \\
\hline Geranial & 1267 & 4,42 \\
\hline Undecanal & 1306 & 0,51 \\
\hline Acetato de citronelila & 1352 & 1,70 \\
\hline Acetato de nerila & 1361 & 5,65 \\
\hline Acetato de geranila & 1381 & 11,75 \\
\hline E-Cariofileno & 1419 & 16,82 \\
\hline$\alpha$-trans-Bergamoteno & 1434 & 2,24 \\
\hline$\alpha$-Humuleno & 1454 & 1,60 \\
\hline Trans-cadina-1(6),4-dieno & 1476 & 1,02 \\
\hline Biciclogermacreno & 1500 & 0,45 \\
\hline$\beta$-Bisaboleno & 1505 & 5,46 \\
\hline$\delta$-Amorpheno & 1512 & 0,60 \\
\hline E-Nerolidol & 1563 & 1,93 \\
\hline Óxido de cariofileno & 1583 & 2,35 \\
\hline epi-囚-Bisabolol & 1682 & 0,67 \\
\hline Pseudofitol & 2018 & 1,04 \\
\hline Hidrocarbonetos monoterpeno & & 15,20 \\
\hline Monoterpenos oxigenados & & 37,53 \\
\hline Hidrocarbonetos sesquiterpenos & & 28,19 \\
\hline Sesquiterpenos oxigenados & & 5,99 \\
\hline Outros & & 0,93 \\
\hline Total & & 87,84 \\
\hline
\end{tabular}


Tabela 2. Porcentagem dos constituintes químicos dos óleos essenciais das cascas dos frutos de C. medica coletados em três diferentes regiões da zona rural de Goiás

\begin{tabular}{|c|c|c|c|c|}
\hline \multirow{3}{*}{ Constituintes } & \multicolumn{4}{|c|}{ Óleo essencial das cascas dos frutos de $\mathbf{C}$. medica } \\
\hline & & Pirenópolis & Jandaia & Santo Antonio do \\
\hline & KI & $\begin{array}{l}\text { Cascas dos } \\
\text { frutos }(\%)\end{array}$ & $\begin{array}{l}\text { Cascas dos } \\
\text { frutos (\%) }\end{array}$ & $\begin{array}{l}\text { Cascas dos } \\
\text { frutos }(\%)\end{array}$ \\
\hline Tricicleno & 926 & 0,32 & - & - \\
\hline$\alpha$-Pineno & 939 & - & 0,29 & 0,41 \\
\hline Sabineno & 975 & 0,14 & - & - \\
\hline$\beta$-Pineno & 979 & 0,36 & 0,27 & 0,18 \\
\hline Mirceno & 990 & 1,97 & 1,94 & 2,41 \\
\hline Limoneno & 1029 & 85,35 & 90,14 & 87,49 \\
\hline Z- $\beta$-Ocimeno & 1037 & 0,91 & 0,58 & 0,84 \\
\hline E- $\beta$-Ocimeno & 1050 & 1,29 & 0,81 & 1,16 \\
\hline Linalol & 1096 & 0,24 & - & 0,35 \\
\hline n-Nonanal & 1100 & 0,15 & - & - \\
\hline Citronelal & 1153 & 0,22 & - & - \\
\hline$\alpha$-Terpineol & 1188 & - & - & 0,19 \\
\hline Citronelol & 1225 & 0,51 & 1,27 & 0,22 \\
\hline Nerol & 1229 & 1,70 & 0,91 & 1,43 \\
\hline Geraniol & 1252 & 0,32 & 1,52 & 2,08 \\
\hline Geranial & 1267 & 2,40 & 1,36 & \\
\hline Undecanona & 1294 & 0,20 & - & - \\
\hline Neril acetato & 1361 & 1,10 & - & 0,22 \\
\hline Geranil acetato & 1381 & 0,29 & - & 0,20 \\
\hline E-Cariofileno & 1419 & 0,91 & - & 0,52 \\
\hline$\alpha$-trans-Bergamoteno & 1434 & 0,34 & - & 0,47 \\
\hline Trans-Cadina-1(6), 4-dieno & 1476 & 0,78 & 0,40 & 1,01 \\
\hline$\beta$-Bisaboleno & 1505 & 0,51 & 0,50 & 0,81 \\
\hline Hidrocarbonetos monoterpenos & & 90,02 & 94,03 & 92,49 \\
\hline Monoterpenos oxigenados & & 6,78 & 5,06 & 4,69 \\
\hline Hidrocarbonetos sesquiterpenos & & 2,54 & 0,90 & 2,81 \\
\hline Sesquiterpenos oxigenados & & - & - & - \\
\hline Outros & & 0,35 & - & - \\
\hline Total identificados (\%) & & 99,69 & 99,99 & 99,99 \\
\hline
\end{tabular}

$(-)=$ não identificados 
Tabela 3. Análise de variância dos óleos essenciais das cascas dos frutos de C. medica

\begin{tabular}{|lllll|}
\hline \multicolumn{5}{|c|}{ Comparação entre os componentes do óleo essencial das cascas dos frutos } \\
\hline FONTES DE VARIAÇÃO & GL & SQ & QM & \\
\hline Tratamentos & & 2 & 12.0 e-06 & 60.0 e-07 \\
\hline Error & 66 & 21.8 e+03 & 330.421 \\
\hline$F=0.0000$ & & & \\
\hline$(p)=0.9999$ & & & \\
\hline
\end{tabular}

Tabela 4. Resumo da análise de variância dos componentes majoritários dos óleos essenciais das cascas dos frutos de $C$. medica

\begin{tabular}{|lllll|}
\hline \multicolumn{5}{|c|}{ Comparação entre os compostos majoritários das cascas dos frutos de C. medica } \\
\hline FONTES DE VARIAÇÃO & GL & SQ & QM & \\
\hline Tratamentos & & 2 & 1.994 & 0.997 \\
\hline Error & 12 & 17.9 e+03 & 14.9 e+02 \\
\hline F $=0.0007$ & & & \\
\hline$(p)=0.9992$ & & & \\
\hline
\end{tabular}

\section{DISCUSSÃO}

Como o aspecto mais crítico da matéria-prima vegetal destinada à produção de preparações fitoterápicas é a sua qualidade ${ }^{(29)}$, o presente trabalho contribuiu com aspectos anatômicos, fitoquímicos e químicos dos óleos essenciais das folhas e cascas dos frutos de $C$. medica, que podem auxiliar no controle de qualidade dessa planta.

Em relação aos estudos anatômicos, os estômatos paracíticos encontrados em C. medica são típicos de Rutaceae ${ }^{(30)} \mathrm{e}$ também foram descritos para outras espécies de Citrus, como C. limon (L.) Burm., C. paradisiMacf., C. reticulata Blanco e C. sinensis (L.) Osbeck ${ }^{(31)}$.

Características encontradas em C. medica, como epiderme unisseriada revestida por cutícula delgada, mesofilo dorsiventral, cristais prismáticos e cavidades secretoras, foram descritas para outras espécies de Rutaceae, dentre elas: Citrus limettioides Tanaka ${ }^{(32)}$, Balfourodendron riedelianum (Engl.) Engl., Helietta apiculata Benth., Metrodorea maracasana Kaastra, Metrodorea nigra A. St.-Hil., Metrodorea stipularis Mart., Metrodorea mollis Taubert e Metrodorea flavida Krause ${ }^{(33)}$ e Raulinoa echinata R. S. Cowan ${ }^{(34)}$.

As cavidades secretoras contendo óleos essenciais são consideradas sinapomorfia para a família Rutaceae ${ }^{(35,36)}$. No pecíolo observaram-se cristais prismáticos no parênquima cortical e medular, assim como descrito para C.sinensise C.limon, enquanto em C. reticulata eles foram observados apenas na região cortical(31).

Observaram-se no pó das folhas feixes vasculares com espessamento em anel, cristais prismáticos e estômatos paracíticos. No pó das cascas dos frutos, grãos de amido e cristais prismáticos. Segundo Oliveira e Akisue ${ }^{(37)}$, a presença de idioblastos contendo inclusões na forma de cristais prismáticos, drusas e areia cristalina constituem-se em detalhes importantes na identificação de drogas vegetais.

Os teores de umidade médios para as cascas dos frutos $(6,22 \%)$ e para as folhas $(8,17 \%)$ estão dentro dos recomendados pela Farmacopeia Brasileira IV ${ }^{(25)}$ (entre 8 e 14\%). De acordo com a literatura, a droga vegetal deve possuir o mínimo de 
umidade para sua boa conservação(38). Recomenda-se que o teor máximo de umidade das drogas vegetais não seja superior a $14 \%$, pois o excesso de umidade em matérias-primas vegetais permite a ação de enzimas, podendo acarretar a degradação de constituintes químicos, além de possibilitar o desenvolvimento de fungos e bactérias ${ }^{(39)}$.

Verificou-se que os componentes majoritários do óleo essencial das folhas foram: E-cariofileno, limoneno e acetato de geranila; e das cascas dos frutos apenas o limoneno. O limoneno também foi encontrado como majoritário no óleo essencial das cascas dos frutos de C. medicavar. cedrate coletados no Irã $(56,6 \%)^{(40)}$. Entretanto, no óleo essencial das cascas dos frutos de $C$. medica coletadas em Bangladesh, identificaram-se como componentes majoritários o isolimoneno (39,37\%), o citral (23,12\%) e o limoneno (21,78\%) e, no óleo essencial das folhas, o erucilamida (28,43\%), o limoneno (18,36\%) e o citral (12,95\%) (6). O limoneno também foi relatado como constituinte majoritário nas cascas dos frutos de outras espécies de Rutaceae, como em Citrus maxima(J. Burman) Merrill. (93,2\%), coletada no Nordeste da Índia(41); Citrus sinensis variedade valenciana (90-93\%), coletada no norte de Santander, Colômbia ${ }^{(42)}$; Citrus reticulata Blanco $(92,4 \%)$, coletada em New Delhi, Índia ${ }^{(43)}$; e Citrus limettioides (70 a 75\%), coletada no Estado de Goiás, Brasil(32). Devido à constatação de alguns compostos químicos diferentes no óleo essencial de C. medica estudado em outros países, fazem-se necessários estudos da atividade medicinal com os espécimes coletados em Goiás.

O limoneno é o principal composto obtido dos óleos essenciais cítricos, sendo utilizado como monômero na fabricação de polímeros, solvente, na composição de produtos de limpeza, nas indústrias de perfumaria, cosmética, farmacêutica e de alimentos $^{(44,45)}$ e na agricultura como repelente ao ácaro rajado Tetranychus urticae Koch ${ }^{(46)}$.

\section{CONCLUSÃo}

Verificaram-se cristais prismáticos tanto nas folhas como na casca dos frutos.

Como a matéria-prima vegetal é normalmente comercializada na forma de droga vegetal (rasurada ou em pó), os dados obtidos nesse trabalho podem contribuir para o controle farmacognóstico da C. medica.

Fazem-se necessários estudos anatômicos comparativos dentro do gênero Citrus para auxiliar no controle de qualidade da droga vegetal comercializada em pó ou razurada.

Os componentes majoritários identificados no óleo essencial das folhas foram E-cariofileno, limoneno e acetato de geranila e das cascas dos frutos o limoneno. Concluiu-se que o teor de limoneno varia dependendo da região de ocorrência, quando comparado com dados na literatura.

Os componentes majoritários do óleo essencial das folhas de C. medica coletadas em Goiás, exceto o limoneno, foram diferentes dos componentes majoritários do óleo essencial das folhas de C. medica relatadas na literatura em outras regiões.

\section{REFERENCES}

1. Stevens PF. Angiosperm Phylogeny Website. Available from: http://www.mobot.org/MOBOT/research/APweb/;2001.

2. Tassara H. Frutas Brasil frutas. 1 ed. São Paulo: Empresa das Artes; 2006.

3. India. The Ayurvedic Pharmacopoeia of India. In: Ayush Do, editor. New Delhi: Ministry of Health and Family Welfare; 2001. p. 27-8.

4. Lorenzi H. Árvores brasileiras: manual de identificação e cultivo de plantas arbóreas nativas do Brasil. 5 ed. Nova Odessa: Instituto Plantarum; 2008. 
5. Fleisher A, Fleisher Z. Aromatic plants of the Holy Land and the Sinai. Part VI. The essential oils of errog (Citrus medica L.). J. Essent. Oil Res. 1991;3(5):377-9.

6. Bhuiyan MNI, J. B, Sardar PK, Rahman MS. Constituents of peel and leaf essential oils of Citrus medica L.. Journal Science Research. 2009;1:387-92.

7. Bhavamishra B. Shi Brahmasankara Mishra and Sri Rupalalaji Vaisya Varanasi: Chaukhambha Sanskrit Sansthan; 2004.

8. Kirtik KR, Basu BD. Indian medicinal plants. Dehra Dun, India: Bishen Singh Mahendra Pal Singh; 1993.

9. Enterazi M, Majd A, Falahian F, Mehrabian S, Hashemi M, Lajimil AA. Antimutagenicity and anticancer effects of Citrus medica fruit juice. Acta Med. Iran. 2009;47(5):373-7.

10. Negi SA, Juyal V, Melkani AB. Analgesic activity of fruit decoction of Citrus medica Linn. J. Pharmaceutical Res. 2010;3(9):211921.

11. Menichini F, Loizzo MR, Bonesi M, Conforti F, De Luca D, Statti GA, et al. Phytochemical profile, antioxidant, anti-inflammatory and hypoglycemic potential of hydroalcoholic extracts from Citrus medica L. cv Diamante flowers, leaves and fruits at two maturity stages. Food Chem. Toxicol. 2011;49(7):1549-55.

12. Nagaraju B, Sanand SC, Ahmed N, Chandra JNNS, Ahed F, Padmavathi GV. Antiulcer activity of aqueous extract of Citrus medica Linn. fruit against ethanol-induced ulcer in rats. Advances in Biological Research. 2012;6(1):24-9.

13. Mohammed AA, Mothana RA, Al-Said MS, El-Tahir KE, Al-Sohaibani M, Rafatullah S. Citrus medica "Otroj": Attenuates Oxidative Stress and Cardiac Dysrhythmia in Isoproterenol-Induced Cardiomyopathy in Rats. Nutrients. 2013;5:4269-83.

14. Sood S, Bansal S, Muthuraman A, Gill NS, Bali M. Therapeutic potential of Citrus medica L. peel extract in carrageenam induced inflammatory pain in rat. Res. J. Med. Plant. 2009;3:123-33.

15. Sah AN, Joshi A, Juyal V, Kumar T. Antidiabetic and hypolipidemic activity of Citrus medica Linn. seed extract in streptomicin incuced diabetic rats. Pharmacog. J. 2011;3(23):80-4.

16. Bairagi GB, Kabra AO, Mandale RJ. Anthelmintic activity of Citrus medica L. leaves in Indian adult earthworm. Int. J. Pharmacol. Res. 2011;3(2):664-7.

17. El-Alfy TS, Hetta MH, Yassin NZ, Rahman RFA, Kadry EM. Estrogenic activity of Citrus medica L. leaves growing in Egypt. J. App. Pharm. Sci. 2012;2(8):180-5.

18. Essien EP, Essien JP, Ita BN, Ebong GA. Physicochemical properties and fungi toxicity of the essential oil of Citrus medica L. against groundnut storage fungi. Turkish J. Bot.. 2008;32:161-4.

19. Patil SJ, Patil SB. Toxicity studies on hepatic, nephric and endocrine organs of Citrus medica seeds extract on of female albino mice. J. Global Pharma Technol. 2011;3:14-21.

20. Simões CMO, Spitzer V. Óleos voláteis. In: Simões CMO, Schenkel EP; Gosmann G, Mello JCP de, Mentz LA, Petrovick PR, editors. Farmacognosia: da planta ao medicamento. 5 ed. Porto Alegre:Editora da UFRGS/Editora da UFSC; 2004. p. 467-95.

21. Cunha AP. Farmacognosia e Fitoquímica. Lisboa: Fundação Calouste Gulbenkian; 2005.

22. Bukastsch F. Bemerkungen zur doppelfärbung astrablausafranin. Mikrokosmos. 1972;61:255.

23. Johansen DA. Plant microtechnique. 1 ed. New York: McGraw-Hill Book; 1940.

24. Costa AF. Farmacognosia. ed., editor. Lisboa: Fundação Calouste Gulbenkian; 2001. 
25. Brasil. Farmacopeia Brasileira. 5. ed. São Paulo: Editora Atheneu; 2010.

26. Van Den Dool H, Kratz PD. Generalization of the retention index system including linear temperature programmed gasliquid partition chromatography. J. Chromatogr. A. 1963;11:463-71.

27. Adams RP. Identification of Essential Oils Components by Gas Chromatography/Quadrupole Mass Spectroscopy. Stream C, editor. Illiois, USA: Allured Publishing Corporation; 2007.

28. NIST. National Institute of Standards and Technology, Version of the NIST/EPA/NIH Mass Spectral Data Base. Gaithersburg: U. S. Department of Commerce; 1998.

29. Yunes RA, Calixto JB. Plantas medicinais sob a ótica da química medicinal moderna. Chapecó: Argos; 2001.

30. Metcalfe CR, Chalk L. Anatomy of the dicotyledons. Oxford: University Press; 1957.

31. Ogundare CS, Saheed SA. Foliar epidermal characters and petiole anatomy of four species of Citrus L. (Rutaceae) from south-western Nigeria Bangladesh. J. Plant Taxon. 2012;19(1):25-31.

32. Lopes LTA, Paula JR, Tresvenzol LMF, Bara MTF, Sá S, Ferri PH, et al. Composição química e atividade antimicrobiana do óleo essencial e anatomia foliar e caulinar de Citrus limettioides Tanaka (Rutaceae). Rev. Ciênc. Farm. Básica Apl. 2013;34(4):503-11.

33. Martins TP, Teixeira SP, Groppo M. Anatomia foliar comparada de Metrodorea A.St.-Hil. (Rutaceae). Simpósio Internacional de Iniciação Científica da USP; Ribeirão Preto, Universidade de São Paulo; 2008.

34. Arioli T, Voltolini CH, Santos M. Morfoanatomia foliar da reófita Raulinoa echinata R.S. Cowan - Rutaceae. Acta Bot. Bras. 2012;22(2):723-32.

35. Cronquist A. An integrated system of classification of flowering plants. New York, USA: The New Botanical Garden; 1981.

36. Judd WS, Campbell CS, Kellogg EA, Stevens PF, Donoghue MJ. Plant Systematics. A phylogenetic approach. Massachusetts, USA: Sinauer Associates, Inc. Publishers Sunderland; 1999.

37. Oliveira F, Akisue G, Akisue MK. Farmacognosia. São Paulo: Atheneu Editora; 1998.

38. Di Stasi LC. Plantas medicinais: arte e ciência. São Paulo: Editora da Universidade Estadual Paulista; 1996.

39. BRASIL. Farmacopeia Brasileira. 4. ed. São Paulo: Editora Atheneu, 2000.

40. Monajemi R, Shahrbanou O, Ali HRS, Ghanadi AR, Abas JD. Cytotoxic effects of essential oils of some iranian Citrus peels. Iran. J. Pharm. Res. 2005;3:183-7.

41. Bordoloi AK, Pathak MG, Sperkova J, Leclercq PA. olatile constituents of the fruit peel oil of Citrus maxima (J. Burman) Merrill. from Northeast India. J. Essent. Oil Res. 1999;11:629-32.

42. Rueda XY, Mancilla LL, Parada DYP. Estudio del aceite esencial de la cáscara de la naranja dulce (Citrus sinensis, Variedad Valenciana) cultivada en Labateca (Norte de Santander, Colombia). Revista de la Facultad Ciências Básicas. 2007;5(1):3-8.

43. Sultana HS, Mohammed A, Husain HS. Variation of the volatile constituents of fruit peels of Citrus reticulata Blanco by physical effects. Int. Res. J. Pharm. 2011;2:62-4.

44. Craveiro AA, Queiroz DC. Óleos essenciais e química fina. Química Nova. 1993;16(3):224-8.

45. Bizzo HR, Hovell AMC, Rezende CM. Óleos essenciais no Brasil: aspectos gerais, desenvolvimento e perspectivas. Química Nova. 2009;32:588-94. 
46. Botelho PS, Moraes MMM, Neves IA, Neves RCS, Ribeiro NC, Born FS, et al. Composição química e ação repelente do óleo essencial da laranja lima (Citrus aurantium L.) sobre o ácaro rajado Tetranychus urticae Koch. Jornada de Ensino, Pesquisa e Extensão (Jepex); Recife; 2009. 